\title{
Innovative Cardio Educational Software System in Support of Medical Education
}

\author{
https://doi.org/10.3991/ijet.v16i22.25207 \\ Galya Georgieva-Tsaneva \\ Bulgarian Academy of Sciences, Sofia, Bulgaria \\ galicanevalabv.bg
}

\begin{abstract}
The article presents an innovative software system that allows for processing and comparative analysis of biomedical data. The presented system uses real cardiological data obtained with modern medical deviceselectrocardiography, continuous Holter monitoring, photoplethysmography device, and others. The software system enables students studying at higher medical universities, majoring in cardiology to get acquainted and acquire skills for working with real cardiac records. The presented system allows the examination and use of cardiac recordings obtained using modern non-invasive technologies for research and procedures-modern electrocardiographic equipment, Holter-monitoring systems, photoplethysmography device. This will enable students to gain prior experience in working with real biomedical patient records. The presented software system together with the traditional training will help to increase the quality of modern education, will contribute to the acquisition of abilities, skills, and competencies necessary for future medical professionals.
\end{abstract}

Keywords-educational software system, medical training, cardiology, data analysis, Mathematical analysis, Holter monitoring

\section{$1 \quad$ Introduction}

The modern rapid development of computer technologies presupposes the use of innovative software systems in all areas of human life. Today, software training systems, along with serious games, videos, and web-based learning resources are increasingly entering the medical education process. Innovative technologies are oriented to function within information systems [7] and to improve their usefulness. Innovative interactive software systems provide the ability to process and analyze large volumes of biomedical data, help increase the efficiency and quality of education in medical specialties. They broaden the horizons of students, enable precise learning of the study material, contribute to the accumulation of experience in working with clinical data, allow for immediate feedback in the learning process and stimulate learners to become better professionals. Future medical professionals have the opportunity to gain experience in diagnosing and prescribing the right choice of treatment, processes that require acquired experience and skills to successfully read the results of research. 
The use of software systems in medical education can be in the following areas: software support for mastering the basic medical sciences; use of software simulations to improve the quality of training and creation of software tests for clinical competence; medical software based training systems; software applications for data use/management [1].

The competency-based approach to medical education [8] has been increasingly developed in recent years due to its obvious benefits (focus on learning outcomes, matching between training and practice, skills development).

The usability of software training systems is defined in terms of the following attributes: learnability, efficiency, memorability, errors, satisfaction [2]. The best software systems must be user-oriented and vital for creating quality applications in all areas [3].

During the process of developing a software system, it is important to use appropriate design principles and methodologies that take into account future users of the system and thus ensure the use, efficiency, and quality of the software information system.

Modern educational systems are increasingly based on computer models for presenting educational content and provide new methods and ways of the educational process [4].

Advances in medicine have made medical education increasingly complex and timeconsuming. For this reason, traditional teaching through teaching and clinical practice alone often proves to be insufficient. The use of software training systems, serious games [5], virtual reality [6] are innovative methods for creating a preliminary experience for students and to higher learning outcomes [7].

\section{Interactive software system to support the training in the medical specialty cardiology}

The presented interactive software system, which can be used to support the education in the medical specialty of cardiology, performs processing and analysis of real cardiac data. The software system was developed and compiled in MATLAB and was created as a standard application for Windows. The demonstration system provides a software implementation of algorithmic methods for the analysis of biomedical data (long cardiac recordings obtained by Holter monitoring and short recordings obtained by electrocardiograph) of patients with various cardiovascular diseases. The software system includes record processing algorithms, a suitable user-oriented graphical interface, algorithms for cardio record analysis.

The following information is maintained for each biomedical record:

- physiological data are stored in the form of numerical values of the amplitude of the cardiac signal and the time during which the signal is read.

- In an information text file, information about the characteristics of the subject is stored: name, age, sex, weight, address and telephone number of the subject; date, recording start, duration, end of recording, recording mode; attending physician, 
diagnosis made by a cardiologist; address of the hospital where the registration was made, etc.

From the actual Holter recording, cardiac intervals are derived using a Waveletbased point localization algorithm with maximum amplitude deviation in the cardio record.

The processing of physiological data is performed after their initial extraction from the file in which they were originally recorded by the Holter device, decompressed, and displayed in a form convenient for further processing - conventional traditional digital record. The presented software program works with the data, which can be obtained in the following ways:

1. Recorded using a Holter device, Lead II (usually 24 hours). The monitoring device is placed early in the morning by a cardiologist on the examined subject, after which he can perform his usual activity.

2. Obtained by electrocardiogram, the data are brief, obtained in a hospital by a medical specialist.

3. Through the use of a photoplethysmographic device [16], they can be obtained both in a hospital and at home in the daily activities of the observed subject.

Pre-processing of the input data is included, which reduces the artifacts; eliminates the deviation at the output level, reduces the noise in the received signal [10], detects QRS complexes (where $\mathrm{Q}, \mathrm{R}$, and $\mathrm{S}$ are the points with maximum deviations of the ECG signal) using an algorithm based on wavelet theory.

The software system includes a data preprocessing module, modules for performing analysis of the studied data, including nonlinear mathematical methods and linear mathematical methods; modules for performing fractal analysis and wavelet analysis of cardiac series. Linear mathematical methods are applied to analyze the time cardiological series in the time domain and the frequency domain, parameters analyzed in these two domains are standardized and their normal values corresponding to healthy individuals can be found in the standard of heart rate variability (HRV) [10]. The model of the presented software system is shown in Figure 1.

All analyzes of the studied data are performed using software-implemented algorithmic mathematical methods. The data obtained after the processing can be stored in a created database and used by students in the process of their education to analyze and compare data from different types of cardiovascular diseases. The results (digital and graphical) can be stored in a dedicated information platform and viewed and compared. This makes it possible to monitor the development of heart disease in patients and to improve the skills of students.

The presented software system is based on mathematical analysis of time sequences formed by the time distances between the individual heartbeats. These time sequences are nonlinear, allow the study of cardiac dynamics, and are known in the scientific literature as heart rate variability. Established in 1996 by eminent scientists and physicians, the HRV standard [10] provides guidelines for HRV testing and defines normal values for healthy individuals. The presented software system is based on these 
instructions, uses the specified normal values, and allows to distinguish the studied individuals from healthy and diseased.

Many years of hard work by researchers from around the world have proven the dependence of heart disease and cardiac events in individuals of different ages when they have reduced heart rate variability. Decreased HRV directly reflects changes in the regulation of the human body by the nervous system [11]. The decreased parasympathetic tone of the nervous system or sympathetic overstimulation leads to a decrease in HRV. Studies have shown that decreased HRV levels (especially for longer periods) are associated with different types of mortality, increased incidence of adverse cardiac events (myocardial infarction, coronary heart disease, risk of sudden death, or congestive heart failure) [12].

HRV can provide additional insight into the pathological and physiological conditions of the human body caused by impaired cardiovascular activity [13]. Heart rate variability today is one of the most promising quantitative indicators for the health of the human body $[14,15]$ and the autonomic activity of the human nervous system.

The software system can save the accumulated data (from the research of individuals), using modern cloud technologies.

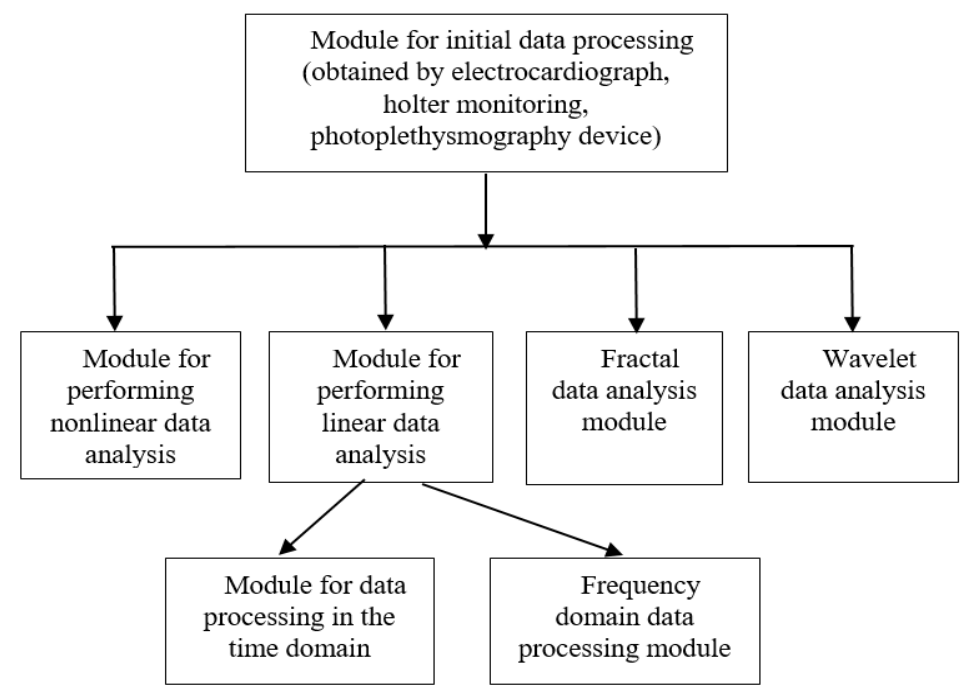

Fig. 1. Software education system to help cardiology students

Input data were collected from individuals diagnosed with the following diseases: heart failure, myocardial infarction, arterial fibrillation, ischemic heart disease, syncope, etc. Thus, cardiology students have the opportunity to observe the similarities and differences in the research and analysis of different groups of cardiovascular diseases and to improve their specialized skills.

Figure 2 shows the cardio intervals obtained from a real Holter record. Localized heartbeats are marked with a rhombus. The average values of the cardio intervals in 
this figure fluctuate around $0.6 \mathrm{sec}$. The time series corresponds to an individual with ischemic heart disease.

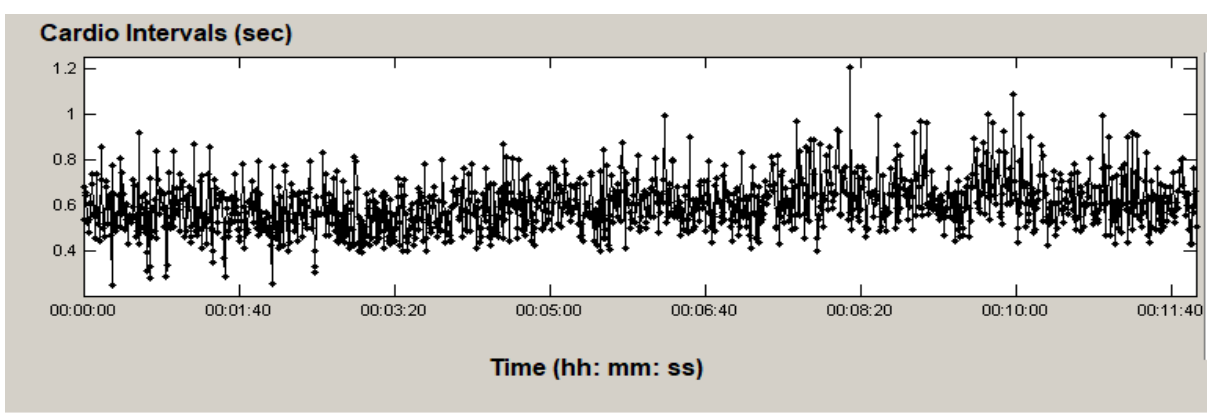

Fig. 2. Cardio Intervals (sec)

The software system makes it possible to display the basic diagnosis of the individual and the diagnosis that was made at the time of admission to the hospital. Figure 3 shows the field for the diagnosis of a patient with ischemic heart disease. The field below shows that the system is currently processing the data and calculating the results in the frequency domain.

The information software system allows searching among the input cardiac records by various indicators, such as basic diagnosis. This enables cardiology students to learn about different real cases of individuals with specific cardiovascular diseases and thus gain valuable experience in recognizing and distinguishing them.

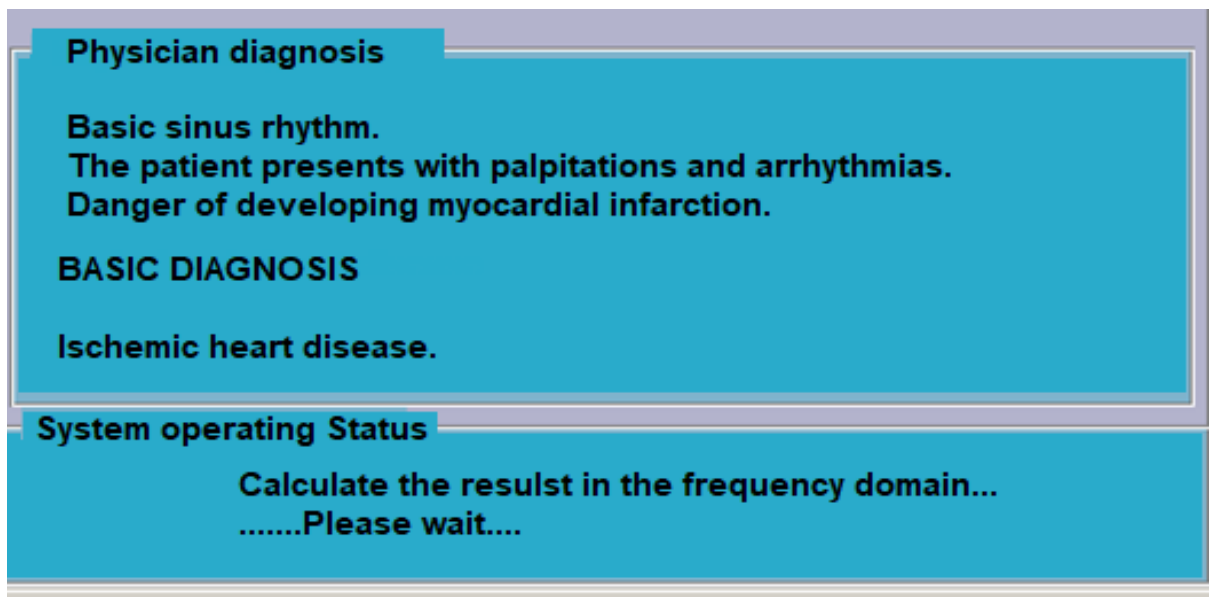

Fig. 3. Diagnosis field

Figure 4 shows the numerical results in tabular form in the frequency domain. The results were obtained using various mathematical methods (Burg, Lomb-Scargle, wavelet). For each calculated frequency parameter (Power in Very Low Frequency domain, Low Frequency domain, and High Frequency domain) the respective reference 
values (from the HRV standard) are indicated, which allows the learner to immediately orientate whether the obtained values are normal or have deviations.

Figure 5 shows graphically the results of the analyzes using the mathematical methods of wavelet theory. The results obtained are for a sick individual. In this type of graphical analysis, the presence of extensive blue fields in the graph shows the low energy of the studied signal (HRV time series), which is an indicator of the disease state of the studied individual. The orange and red fields in the graph show the high energy of the signal being studied.

\begin{tabular}{|c|c|c|c|c|c|c|c|}
\hline $\begin{array}{l}\text { Frequency } \\
\text { band }\end{array}$ & $\begin{array}{r}\text { Peak } \\
(\mathrm{Hz}) \\
\end{array}$ & $\begin{array}{r}\text { Power } \\
\left(\mathrm{ms}^{2}\right)\end{array}$ & $\begin{array}{r}\text { Reference } \\
\text { values }\end{array}$ & $\begin{array}{r}\text { Power } \\
(\%) \\
\end{array}$ & $\begin{array}{r}\text { Power } \\
\text { (n.u.) } \\
\end{array}$ & $\begin{array}{r}\text { Reference } \\
\text { values } \\
\end{array}$ & $\begin{array}{r}\text { LF/HF(ratio) } \\
\text { n.u.1.5-2.0 } \\
\end{array}$ \\
\hline \multicolumn{8}{|l|}{ Burg } \\
\hline VLF & 0.04 & 190.3 & - & 7.10 & & - & 0.358 \\
\hline LF & 0.13 & 658.9 & $1170 \pm 416$ & 24.50 & 0.264 & $54 \pm 4$ & 0.000 \\
\hline HF & 0.30 & 1838.8 & $975 \pm 203$ & 68.40 & 0.736 & $29 \pm 3$ & \\
\hline \multicolumn{8}{|c|}{ Lomb-Scargle } \\
\hline VLF & 0.04 & 6.9 & - & 3.6 & & - & 0.306 \\
\hline LF & 0.12 & 43.8 & $1170 \pm 416$ & 22.6 & 0.234 & $54 \pm 4$ & 0.000 \\
\hline HF & 0.30 & 143.2 & $975 \pm 203$ & 73.9 & 0.766 & $29 \pm 3$ & \\
\hline \multicolumn{8}{|l|}{ Wavelet } \\
\hline VLF & 0.01 & 1127.1 & - & 15.2 & & - & 0.341 \\
\hline LF & 0.12 & 1603.6 & $1170 \pm 416$ & 21.6 & 0.254 & $54 \pm 4$ & 20.333 \\
\hline $\mathrm{HF}$ & 0.32 & 4699.5 & $975 \pm 203$ & 63.2 & 0.746 & $29 \pm 3$ & \\
\hline
\end{tabular}

Fig. 4. Tabular results

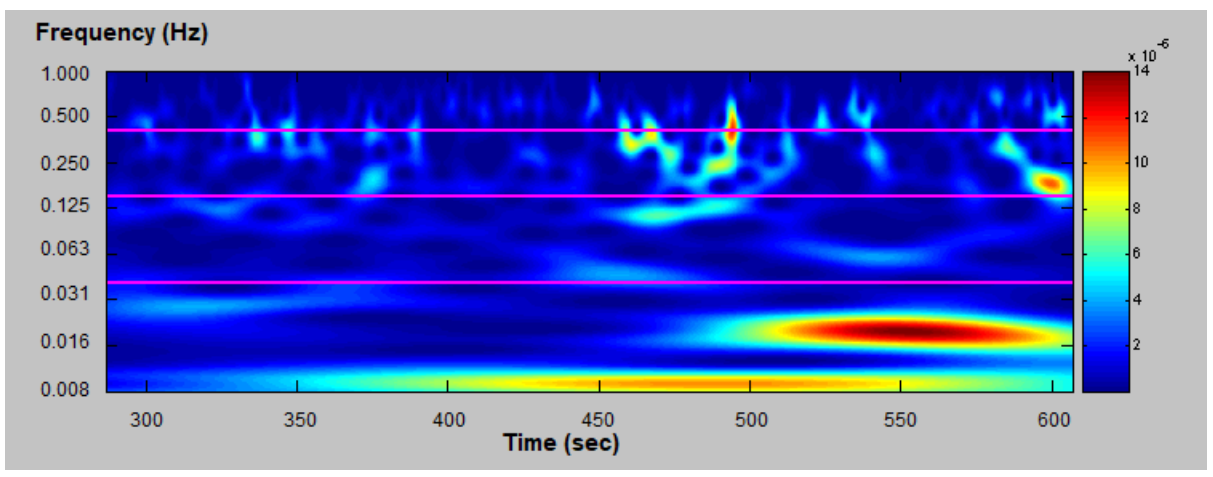

Fig. 5. Presentation of the graphical results based on wavelet theory

The presented software system allows building in medical students approaches to interpret cardiac data, research, as well as the results of mathematical analyzes. The information system provides an opportunity to increase the educational skills of students, providing them with opportunities to gain experience in diagnosing and making decisions for effective therapy of patients.

\section{Conclusion}

For the creation of specialists in their specialized field, possessing the necessary skills for their activity, the quality of medical education is of great importance. The 
inclusion in the learning process of innovative educational tools such as interactive software systems, videos, serious games, simulations, virtual reality leads to improving the quality of training of future doctors. The presented information educational system unites all modern mathematical methods, the application of which has proved to be effective in the scientific and clinical study of the activity of the cardiovascular system. Software systems in medical education are modern tools for processing, analysis, storage, and use of biomedical information, with which students can gain valuable experience that will be useful in their future work as specialists.

\section{$4 \quad$ Acknowledgment}

This research work was carried out as part of the scientific project "Investigation of the application of new mathematical methods for the analysis of cardiac data" No KP06-N22/5, date 07.12.2018, funded by the National Science Fund of Bulgaria (BNSF).

\section{$5 \quad$ References}

[1] The United States. Congress. Office of Technology Assessment. (1979). Computer Technology in Medical Education and Assessment. Background report. U.S. Government Printing Office Washington, https://ota.fas.org/reports/7903

[2] Nielsen, J. (2009). What is Usability?. In User Experience Re-Mastered, by Chauncey Wilson, 4-7. Morgan Kaufmann.

[3] Lalband N., D. Kavitha. (2019). Software Engineering for Smart Healthcare Applications, International Journal of Innovative Technology and Exploring Engineering (IJITEE), ISSN: 2278-3075, Vol, 8, Iss. 6S4, Corpus ID: 212512152 https://doi.org/10.35940/ijitee.f1066. $\underline{0486 s 419}$

[4] Braga J., Mendes J. B., Caponetto G. and Ramos A. (2009). Software Model For Computer Based Training. IADIS International Conference on Applied Computing At LisbonVol.1.

[5] Georgieva-Tsaneva, G. (2019). Serious Games and Innovative Technologies in Medical Education in Bulgaria. TEM Journal. Volume 8, Issue 4, Pages 1398-1403.

[6] Bertram J., J. Moskaliuk, and U. Cress. (2015). Virtual training: Making reality work. Comput. Human Behav., vol. 43, pp. 284-292, https://doi.org/10.1016/i.chb.2014.10.032

[7] Sattar M. U., Palaniappan S., Lokman A., Shah N., Khalid U., Hasan R., 2020. Motivating Medical Students Using Virtual Reality Based Edu-cation, iJET - Vol. 15, No. 2, pp.160174, https://doi.org/10.3991/ijet.v15i02.11394

[8] Maltabarova N., Kokoshko A., Abduldayeva A., Shanazarov N., Smailova G. 2019. Innovation Technologies in Student's Independent Activity and Creativity Development: The Case of Medical Education. iJET - Vol. 14, No. 11, pp. 32- 40, https://doi.org/10.3991/ ijet.v14i11.10341

[9] Baizak, U., Kudabayev, K., Dzhazdykbayeva, M., Assilbekova, G., Baizakova, B., Mintassova, A. (2017). Competency-based Approach to the Assessment of Professional Training for a Medical Student to Work with Medical Equipment.International Journal of Emerging Technologies in Learning (iJET),12(06): 108-119. https://doi.org/10.3991/ijet. $\underline{\mathrm{v} 12 \mathrm{i} 06.7008}$ 
[10] Malik, M., (1996). Task Force of the European Society of Cardiology and the North American Society of Pacing and Electrophysiology. Heart Rate Variability: Standards of Measurement, Physiological Interpretation, and Clinical Use. Circulation, 93, pp. 1043-1065. https://doi.org/10.1111/j.1542-474x.1996.tb00275.x

[11] Schuit A J, L G van Amelsvoort, T C Verheij, R D Rijneke, A C Maan, C A Swenne, E G Schouten, (1999), Exercise training and heart rate variability in older people, Med Sci Sports Exerc., 31(6):8, pp.16-21. https://doi.org/10.1097/00005768-199906000-00009

[12] Melanson E L, (2000), Resting heart rate variability in men varying in habitual physical activity, Med Sci Sports Exerc.; 32(11), pp.1894-901. https://doi.org/10.1097/00005768200011000-00012

[13] Georgieva-Tsaneva, G., (2019). Mathematical Processing of Cardiological Signals and Organization of Access to Holter Databases: Guide for Accessing Data From People With Visual Deficits. In Dimitrova, M., \& Wagatsuma, H. (Ed.), Cyber-Physical Systems for Social Applications, pp. 286-304. Dimitrova, M., Wagatsuma, H., Eds.; IGI Global: Hershey, PA, USA. http://doi:10.4018/978-1-5225-7879-6.ch012

[14] Georgieva-Tsaneva, G. 2019. Frequency Analysis of Cardiac Data Obtained through Holter Monitoring in Real Living Conditions. In Proceedings of CBU International Conference Proceedings, 7, https://ojs.journals.cz/index.php/CBUIC/article/view/1498.

[15] Gospodinova, E. (2019). Time Series Analysis Using Fractal and Multifractal Methods. In Proceedings of the 20th International Conference on Computer Systems and Technologies, ACM, New York, NY, USA, 188-193, https://doi.org/10.1145/3345252.3345265

[16] Gospodinov, M., Cheshmedzhiev, K. (2019). Three-sensor portable information system for physiological data registration, ACM International Conference Proceeding Series, 2019, pp. 36-41. https://doi.org/10.1145/3345252.3345281

\section{Author}

Galya Georgieva-Tsaneva, Ph.D. is an Assistant Professor at the Institute of Robotics, Bulgarian Academy of Sciences, Sofia, Bulgaria. Her scientific research interests include medical information systems, serious educational games, investigation of Heart Rate Variability of ECG data, wavelet and fractal analysis, web accessibility, coding and compression of information, fractal modeling, computer networks and communications, teletraffic engineering. She is the author/co-author of 3 chapters in scientific books and has published about 90 scientific articles nationally and internationally. She is a member of the Union of Informatics and Automation in Bulgaria, a member of the editorial board of international scientific journals.

Article submitted 2021-07-02. Resubmitted 2021-08-26. Final acceptance 2021-08-27. Final version published as submitted by the author. 